\title{
Controversies in the determination of energy requirements
}

\author{
C. Elizabeth Weekes \\ Department of Nutrition \& Dietetics, Guy's \& St Thomas' NHS Foundation Trust, Lambeth Palace Road, London \\ SE1 7EH, UK
}

\begin{abstract}
To avoid any negative outcomes associated with under- or overfeeding it is essential to estimate nutrient requirements before commencing nutrition support. The energy requirements of an individual vary with current and past nutritional status, clinical condition, physical activity and the goals and likely duration of treatment. The evidence-base for prediction methods in current use, however, is poor and the equations are thus open to misinterpretation. In addition, most methods require an accurate measurement of current weight, which is problematic in some clinical situations. The estimation of energy requirements is so challenging in some conditions, e.g. critical illness, obesity and liver disease, that it is recommended that expenditure be measured on an individual basis by indirect calorimetry. Not only is this technique relatively expensive, but in the clinical setting there are several obstacles that may complicate, and thus affect the accuracy of, any such measurements. A review of relevant disease-specific literature may assist in the determination of energy requirements for some patient groups, but the energy requirements for a number of clinical conditions have yet to be established. Regardless of the method used, estimated energy requirements should be interpreted with care and only used as a starting point. Practitioners should regularly review the patient and reassess requirements to take account of any major changes in clinical condition, nutritional status, activity level and goals of treatment. There is a need for large randomised controlled trials that compare the effects of different levels of feeding on clinical outcomes in different disease states and care settings.
\end{abstract}

Energy requirements in clinical conditions: Prediction methods: Indirect calorimetry: Accuracy of estimation

To avoid any negative outcomes associated with underor overfeeding a patient's energy (and other nutrient) requirements should be estimated before commencing nutrition support (National Institute for Health and Clinical Excellence, 2006). The energy requirements of an individual, however, vary with a number of variables, including age, gender, body composition, current and past nutritional status, clinical condition, physical activity and the goals and likely duration of nutritional treatment. Currently, no method exists that takes account of all these variables, and dietitians (and other clinicians) are required to exercise a considerable extent of clinical judgement when determining the energy requirements of an individual patient.

In healthy individuals total energy expenditure (TEE) comprises BMR, dietary-induced thermogenesis (energy expended in the digestion, absorption and transport of nutrients) and physical activity (Fig. 1). BMR can be defined as the metabolic activity required to maintain life, including respiration, heart beat and maintenance of body temperature. In any individual the measured BMR is highly reproducible. However, the CV between individuals is $5-10 \%$ of the mean, mainly because of variability in the relationship between height, weight and body composition, differences in the proportions of metabolically-active organs and tissues, variations in thyroid function and circadian rhythms. Conditions essential for the measurement of BMR include the subject being post-absorptive $(12 \mathrm{~h}$ fast), lying still at physical and mental rest in a thermoneutral environment $\left(27-29^{\circ} \mathrm{C}\right)$, having had no artificial stimulants such as tea, coffee or nicotine in the previous $12 \mathrm{~h}$ and having undertaken no heavy physical activity during the previous day. If any of these criteria are not met, the measurement obtained is described as resting energy expenditure (REE). In the clinical situation it is 
Total energy expenditure

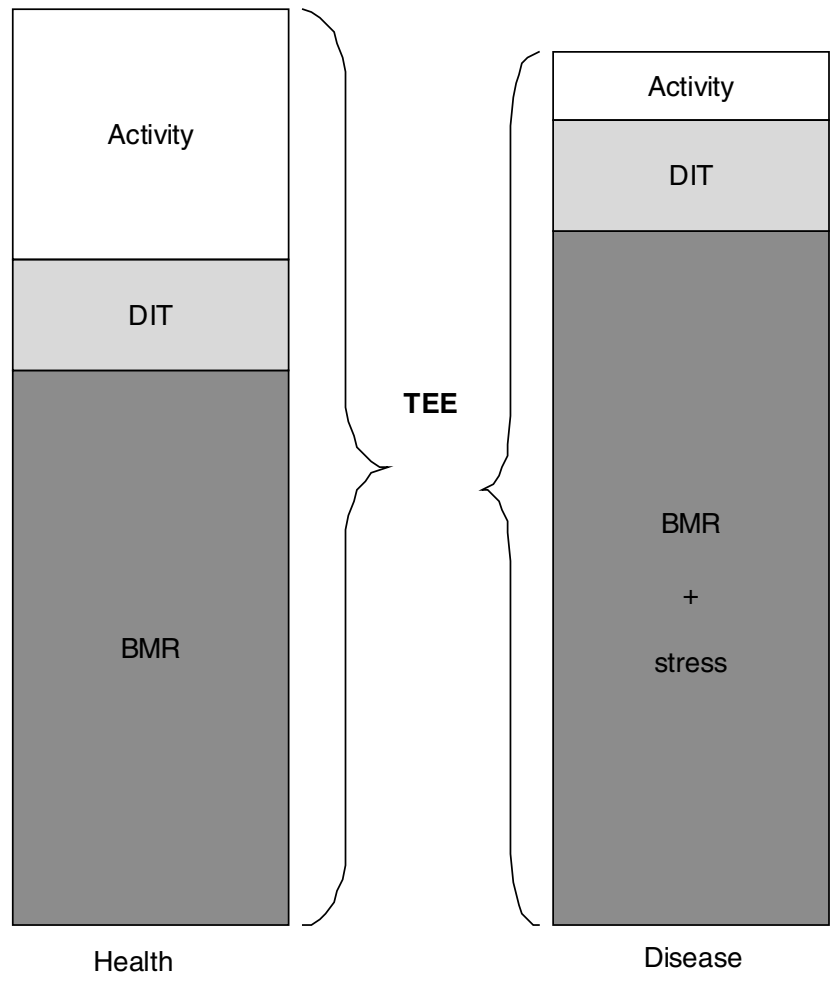

Fig. 1. Total energy expenditure (TEE) in health and disease. DIT, dietary-induced thermogenesis.

rarely possible to measure BMR, thus in sick or injured subjects REE will comprise BMR plus the effect of any metabolic response to injury or disease, and may include some proportion of dietary-induced thermogenesis if the subject is not post-absorptive. In some patients, such as those with involuntary movements as a result of neuromuscular dysfunction, an element of physical activity may also be included during measurements of energy expenditure. While metabolic stress may increase energy expenditure, injury and disease are usually accompanied by a decrease in physical activity that more than compensates for the increase resulting from stress. TEE in patients may, therefore, be similar to or less than that in healthy individuals (Elia, 1995; Fig. 1).

In the clinical situation the two methods used most frequently are prediction equations and indirect calorimetry. The present paper will highlight the advantages and disadvantages of each method using the intensive treatment unit (ITU) population to illustrate the discussion.

By far the greatest proportion of studies of energy expenditure has been conducted on critically-ill patients; however, many of the issues raised will apply to other disease states and healthcare settings. Reported energy expenditure in patients in the ITU varies considerably (Table 1), partly as a result of the heterogeneity of different ITU populations and also partly because of differences in definitions of critical illness and/or sepsis. In addition to the factors that affect energy expenditure in general, i.e. age, gender, weight and body composition, there are other factors that affect the energy expenditure of patients in the ITU in particular (Table 2). Thus, in the ITU setting the estimation of an individual patient's energy requirements can be very challenging.

\section{Prediction equations}

Measurements of energy expenditure by direct or indirect calorimetry or the doubly-labelled-water method are the most accurate methods for determining energy requirements. In the clinical situation in the UK, however, these methods are usually impractical because they are expensive, time-consuming and require trained personnel to perform them. As a result, a considerable number of prediction equations have been published over the past 40 years in an attempt to develop more practical tools for determining energy requirements in the clinical setting. While usually quick and easy to use, inexpensive and universally available, all prediction equations are open to criticism for a number of reasons. All the equations require an assessment of current weight and they have not been adequately validated. While the equations may accurately predict energy requirements for specific populations, they have a poor predictive value for individuals. In addition, all methods require some extent of clinical judgement and are therefore open to misinterpretation.

The basis of several prediction methods is an estimation of BMR (Wilmore, 1977; Long et al. 1979; Elia, 1990; Todorovic \& Micklewright, 2004) to which is added a 'stress' or 'injury' factor to take account of the changes in energy expenditure presumed to have resulted from illness or injury. During the early part of the 20th century BMR measurements such as those conducted by Harris \& Benedict (1919; HBE) were primarily used to diagnose hypo- and hyperthyroidism. It was not until the 1980s that a publication by the Food and Agriculture Organization/ World Health Organization/United Nations University (1985) used measurements of energy expenditure (including BMR), rather than food intake, to estimate energy requirements. In the USA the most-commonly-used BMR prediction equations are those developed by Harris \& Benedict (1919; HBE), yet they are open to criticism. The equations were developed from measurements conducted on 136 males and 103 females over a 10-year period between 1909 and 1917, about one century ago. The subjects were considered healthy and 'normal' for that time, but compared with current populations were young (females, 27 (SD 9) years; males, 31 (SD 14) years) and lean (BMI: females, 21.4 (SD 2.8$) \mathrm{kg} / \mathrm{m}^{2}$; males, 21.5 (SD $4 \cdot 1) \mathrm{kg} / \mathrm{m}^{2}$ ). The predictive value of the HBE for young females is poor, a fact later recognised by Benedict himself (Benedict, 1928), and more recent studies comparing the HBE with measured BMR in healthy populations show that the HBE consistently overestimate by $5-15 \%$ (Daly et al. 1985; Mifflin et al. 1990). The Schofield equations were developed more recently as the basis for the Food and Agriculture Organization/World Health Organization/ United Nations University (1985) report and are commonly used in Europe and other parts of the world. The equations were developed from a meta-analysis of about 100 studies 
Table 1. Measured energy expenditure in the intensive treatment unit (ITU) (Mean values and standard deviations)

\begin{tabular}{|c|c|c|c|c|c|}
\hline \multirow[b]{3}{*}{ Reference } & \multirow[b]{3}{*}{ ITU population } & \multicolumn{4}{|c|}{ REE } \\
\hline & & \multicolumn{2}{|c|}{$\mathrm{kJ} / \mathrm{d}$} & \multicolumn{2}{|c|}{$\mathrm{kcal} / \mathrm{d}$} \\
\hline & & Mean & SD & Mean & SD \\
\hline Swinamer et al. (1987) & 10, General & 9158 & 1396 & 2191 & 334 \\
\hline Flancbaum et al. (1999) & 30, General & 8377 & 1940 & 2004 & 464 \\
\hline Weijs \& Kruizenga (2006) & 78, General & 8084 & 1689 & 1934 & 404 \\
\hline Liggett \& Renfro (1990) & 73, Medical & 6625 & 435 & 1585 & 104 \\
\hline Smyrnios et al. (1997) & 8, Medical & 6628 & 2031 & 1490 & 486 \\
\hline Faisy et al. (2003) & 70, Medical & 7900 & 1689 & 1890 & 404 \\
\hline Hunter et al. (1988) & 20 , Surgical & 5777 & 543 & 1382 & 130 \\
\hline Cortes \& Nelson (1989) & 31, Surgical & 7725 & 2048 & 1848 & 490 \\
\hline Hwang et al. (1993) & 15, Trauma & 9263 & 418 & 2216 & 100 \\
\hline Boulanger et al. (1994) & 115, Trauma & 8577 & 2220 & 2052 & 531 \\
\hline Franch-Arcas et al. (1994) & 9, Trauma & 9347 & 585 & 2236 & 140 \\
\hline Hwang et al. (1993) & 15, Sepsis & 7867 & 527 & 1882 & 126 \\
\hline Plank et al. (1998) & 8, Sepsis & 7863 & 477 & 1881 & 114 \\
\hline Barak et al. (2002) & 15, Sepsis & 8389 & 1831 & 2007 & 438 \\
\hline
\end{tabular}

REE, resting energy expenditure.

Table 2. Factors affecting measured energy expenditure in patients in the intensive treatment unit

\begin{tabular}{|c|c|}
\hline Patient & $\begin{array}{l}\text { Diagnosis, e.g. head injury, cardiac surgery, } \\
\text { infection } \\
\text { Metabolic state } \\
\text { Sepsis } \\
\text { Multi-organ failure } \\
\text { Co-morbidities, e.g. obesity, diabetes mellitus, } \\
\text { cardiac or respiratory disease } \\
\text { Level of consciousness } \\
\text { Nutritional status } \\
\text { Nutritional intake } \\
\text { Body temperature } \\
\text { Respiratory rate }\end{array}$ \\
\hline Treatment & $\begin{array}{l}\text { Pharmaceutical agents, } \\
\text { e.g. sedation, analgesia } \\
\text { Ventilation mode } \\
\text { Surgery } \\
\text { Investigations and procedures, } \\
\quad \text { e.g. haemo-filtration } \\
\text { Activity (passive or active) } \\
\text { Ambient temperature and humidity }\end{array}$ \\
\hline Methodology & $\begin{array}{l}\text { Timing post insult } \\
\text { Length of measurement (steady-state achieved) } \\
\text { Time of day } \\
\text { Fraction of inspired } \mathrm{O}_{2} \\
\text { Possible leaks, e.g. from chest tubes } \\
\text { or uncuffed endo-tracheal tubes }\end{array}$ \\
\hline
\end{tabular}

conducted over a long time period (1914-1980), including the subjects studied by Harris \& Benedict (1919). However, these equations have also been shown to overestimate BMR in many contemporary populations (Henry, 2005). This disparity is in part because the database is skewed towards a younger population, with only eighty-eight subjects $(1.2 \%$ of the total subjects) aged $>60$ years.
Furthermore, the database contains a disproportionate number of Italian subjects (3388 of 7173; 47\%), who were found to have a higher BMR on a per kilogram body weight basis than any of the other study populations; possibly because two-thirds of the subjects (2279 of 3388; $67 \%$ ) were young men who were leading physically-active lives, either in military service or employed as miners and labourers. Recently, a series of newer BMR prediction equations has been developed (Henry, 2005). These equations take account of many of the earlier criticisms and they tend to produce lower BMR values than the current Food and Agriculture Organization/World Health Organization/United Nations University (1985) equations. These newer equations have yet to be fully validated, and their future use and application will depend on their ability to predict BMR more accurately in contemporary populations. Whichever BMR prediction equation is used in the clinical situation, it must be noted that all equations have been derived from healthy populations and therefore may not be an ideal baseline for estimating requirements in sick or injured individuals.

In addition to details on age and gender these BMR equations require a current weight. While it is possible to obtain a reliable weight in many hospitalised patients, especially with the increasing availability of chair, hoist and bed scales, achieving an accurate weight still remains problematic in a considerable number of patients, in particular those with impaired balance or mobility, patients with open wounds and those attached to medical equipment such as ventilators. Furthermore, an increasing number of patients are being fed by artificial nutrition support at home, yet many are bed-bound or immobile and therefore difficult to weigh. Fluid retention also makes it difficult to assess true body weight. In critically-ill patients the accumulation of 10-20 litres extracellular fluid may occur during the acute phase of injury (Lobo et al. 2006) and in patients with liver disease similar amounts of fluid may 


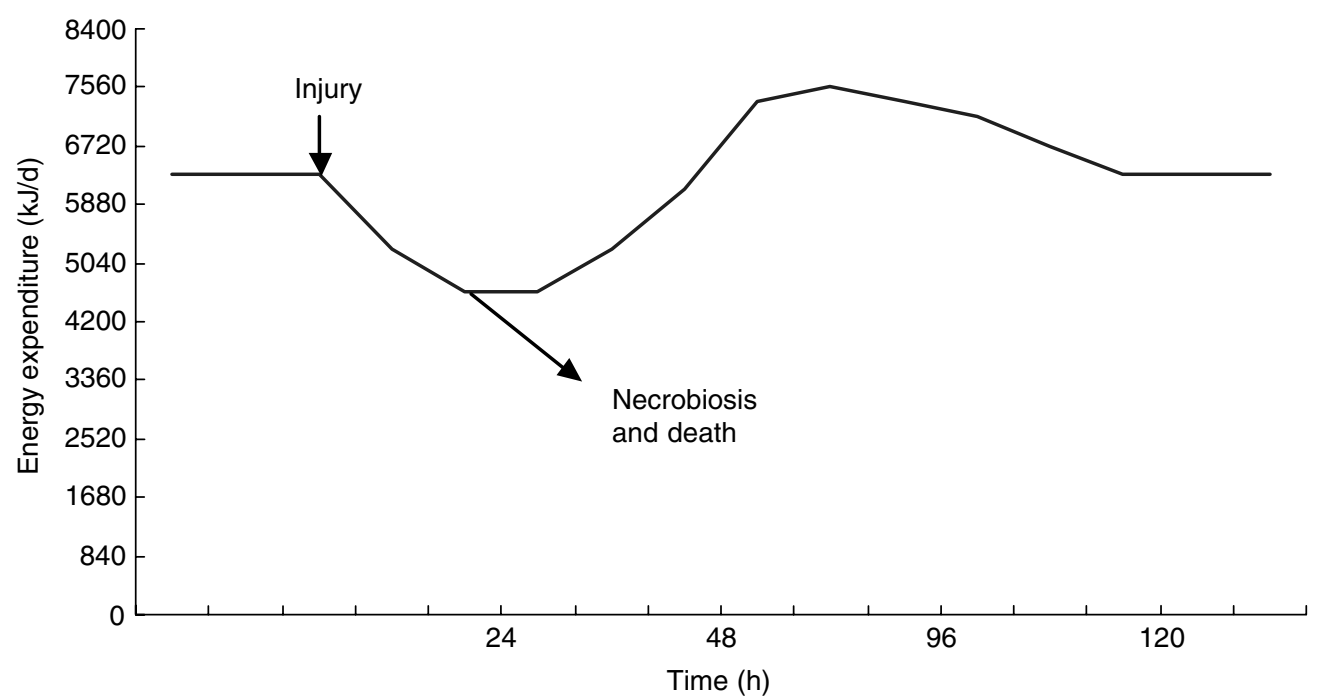

Fig. 2. The effects of the metabolic response to injury on energy expenditure $(k J / d)$.

accumulate as ascites. Even the ankle oedema commonly seen in malnutrition and in chronic diseases such as chronic obstructive pulmonary disease may make a major contribution to a patient's body weight. However, fluid retention increases body weight without increasing metabolically-active tissue and therefore, where possible, 'dry' weight should be recorded and used to calculate BMR. For example, post-dialysis weight should be used in renal patients or weight following drainage of ascites in liver disease (Madden \& Wicks, 1994). In patients in the ITU who have undergone surgery it has been shown (Weissman \& Kemper, 1992) that subtracting the weight of cumulative net fluid balance from post-operative weight accurately reflects preoperative weight. In the absence of hoist or bed scales in the ITU it is common practice for clinicians to estimate a patient's weight and use this estimate for calculating energy requirements and drug doses. This method relies on clinical judgement and, to date, there appear to be no studies using clinician-estimated weight compared with, for example, last known weight, in relation to estimating energy requirements in patients in the ITU. In conscious and orientated patients self-reported weight can be used as a surrogate for measured weight, although it is less reliable in obese individuals who tend to underestimate their weight and lean individuals who tend to overestimate their weight (Rowland, 1990; Roberts, 1995; Elia, 2003; Ruivo et al. 2004).

In a recent review Reeves \& Capra (2003) have attempted to determine the evidence-base of a number of current prediction methods (Wilmore, 1977; Long et al. 1979; Elia, 1990; Todorovic \& Micklewright, 1997). The authors conclude that the original data on which the methods were based are difficult to locate, that the methods tend to be based on expert opinion or consensus statement rather than experimental evidence and that there is a lack of information on how the methods were derived. Furthermore, none of the methods has been adequately validated.

A number of studies have compared a variety of prediction equations with measured energy expenditure
(MEE) in different ITU populations (Carlsson et al. 1984; van Lanschot et al. 1986; Weissman et al. 1986; Swinamer et al. 1987; Hunter et al. 1988; Cortes \& Nelson, 1989; Casati et al. 1996; Flancbaum et al. 1999; Cheng et al. 2002). While the majority have found that prediction equations tend to overestimate requirements compared with MEE and that all equations have a poor predictive value for individuals, it was not always the case. This inconsistency may in part be because some investigators have compared MEE with a BMR equation such as $\mathrm{HBE}$ (Weissman et al. 1986; Swinamer et al. 1987; Hunter et al. 1988), others have compared MEE with predicted BMR plus variable stress and/or activity factors (Carlsson et al. 1984; van Lanschot et al. 1986; Cortes \& Nelson, 1989; Casati et al. 1996; Cheng et al. 2002) and others have compared MEE with equations derived specifically for ITU populations (Flancbaum et al. 1999; Cheng et al. 2002). None of the studies has given specific details of the clinical variables used to assign the stress factors, nor have they commented on the profession, knowledge and experience of the individual calculating the predicted requirements.

Prediction equations that state a range (for example, see European Society for Parenteral and Enteral Nutrition guidelines; Kreymann et al. 2006) and those that require the use of stress factors (for example, see Parenteral and Enteral Nutrition Group of the British Dietetic Association guidelines; Todorovic \& Micklewright, 2004) rely on clinical judgement, and may therefore be open to misinterpretation, especially in those users who are unfamiliar with the evidence-base (Glynn et al. 1999; Barak et al. 2002; Reeves \& Capra, 2003). During the past three decades prescribed energy requirements for critically-ill patients have been revised downwards, in part because of changes in the measurement and interpretation of energy expenditure and in part as a result of changes in therapeutic techniques. In early studies measurements of energy expenditure were frequently made close to the time of peak hypermetabolism (i.e. the first few days of injury or illness) and then extrapolated, inappropriately, to much longer periods (Fig. 2). For example, Vermeij et al. (1989) have 
found that when TEE on day 1 is used to estimate TEE on subsequent days in sixty patients who have undergone surgery and are mechanically ventilated errors of $\leq 31 \%$ of actual TEE occur. Also, reported measurements were often conducted while patients were receiving hyperalimentation', i.e. large amounts of parenteral nutrition (either continuously or intermittently), and therefore a sizable proportion of dietary-induced thermogenesis may have been included in the measurement (Elia \& Jebb, 1992).

A number of therapeutic interventions have been shown to either increase or decrease energy expenditure. For example, in the past it was the practice to attempt to cool patients with pyrexia by lowering ambient temperature. However, this practice caused an increase in thermogenesis as the body attempted to maintain a high core temperature. More recently, heat loss, and therefore energy expenditure, has been minimised by nursing patients at a higher ambient temperature, i.e. in a thermo-neutral environment (Elwyn et al. 1981). Other changes that have reduced both the magnitude and duration of the stress response in the past two decades include: the elective and early surgical removal of necrotic tissue, drainage of abscesses, the early diagnosis and aggressive management of infections (Elia, 1995); reduction in the use of corticosteroids in closed head injury (Greenblatt et al. 1989); use of ibuprofen in burn injury (Wallace et al. 1992); re-warming of patients following coronary-artery bypass surgery (Hanhela et al. 1999); the use of effective sedation and paralysis in patients who are mechanically ventilated (Bruder et al. 1998; Terao et al. 2003).

Some of the prediction equations (Todorovic \& Micklewright, 2004) require the clinician to add a factor for activity, yet the factor assigned is dependent on clinical judgement. The effects of physical activity on TEE depend on tissue mass and type of activity, its intensity, duration and frequency, yet in routine clinical practice these variables are rarely, if ever, formally assessed. While there are recommendations for activity factors for use in hospitalised patients (Elia, 1990), the source data for these guidelines are difficult to locate. In the ITU setting activities such as weighing on a sling-type bed scale, repositioning and chest physiotherapy result in an increase in energy expenditure of $20-30 \%$. However, the effect is transient, lasting $\leq 30 \mathrm{~min}$ post intervention, and therefore the contribution of such activities to TEE is likely to be small, i.e. 5-10\% (Weissman et al. 1986; Swinamer et al. 1987). A literature review reveals a paucity of studies measuring the effects on physical activity (and thus energy expenditure) of abnormal neuromuscular function such as motor neurone disease, passive and active physiotherapy, the increased effort involved in moving injured and/or painful limbs and mechanical inefficiency, e.g. secondary to chronic obstructive pulmonary disease. The few studies available, e.g. in cerebral palsy (Johnson et al. 1997), heredity neuro-muscular disease (McCrory et al. 1998), Parkinson's disease (Toth et al. 1997) and hip fracture (Miller et al. 2005), suggest that the effects on TEE are very variable and require further investigation. Furthermore, an increasing number of patients are being discharged home on artificial nutritional support and, while a large proportion is house-bound, there are a number of patients who regularly leave the house to socialise or even work, albeit part-time. While the physical activity levels in the Department of Health (1991) report may apply to some patients in the latter group, there is a need to conduct more research on the effects of physical activity TEE in different clinical conditions.

An alternative simpler method for determining energy requirements is one based on set energy values expressed on a per $\mathrm{kg}$ body weight basis. For example, recent recommendations include $84-105 \mathrm{~kJ}(20-25 \mathrm{kcal}) / \mathrm{kg}$ body weight for critically-ill patients (Kreymann et al. 2006) and $105-146 \mathrm{~kJ}(25-35 \mathrm{kcal}) / \mathrm{kg}$ body weight for patients who are not severely ill or injured, nor at risk of re-feeding syndrome (National Institute for Health and Clinical Excellence, 2006). Other authors have recommended different cut-offs for the same disease states (American Society for Parenteral and Enteral Nutrition Board of Directors, 2002). The method appears to have been originally derived for critically-ill patients who are mechanically ventilated, yet explanations of how the values were derived or references to original work are difficult to locate and there appear to be no studies validating this method in critically-ill or other patient groups. It is unclear if the method is valid for use in underweight or obese subjects and, if it is, whether clinicians should use actual, ideal or adjusted body weight. Furthermore, the method does not take account of differences in energy expenditure resulting from differences in age or gender. In addition to a lack of validation, there appears to be no guidance on how to determine where in the range a particular patient might be placed. For example, what variables should be used to determine whether a metabolically-stable patient post surgery with a BMI in the acceptable range $\left(20-25 \mathrm{~kg} / \mathrm{m}^{2}\right)$ receives $84(20), 105(30)$ or $146(35) \mathrm{kJ}(\mathrm{kcal}) / \mathrm{kg}$ body weight per d? Currently, the level used depends on clinical judgement and the experience and knowledge of the practitioner. Studies in ITU populations have shown that REE on a per $\mathrm{kg}$ body weight basis can vary considerably from as low as $42 \mathrm{~kJ}(10 \mathrm{kcal})$ to $>209 \mathrm{~kJ}$ ( $50 \mathrm{kcal}$; Frankenfield et al. 1994; Green et al. 1995; McClave et al. 1998; Reid \& Campbell, 2001; Barak et al. 2002), and in patients with sepsis the reported ranges are even greater, varying from $60 \mathrm{~kJ}(14.4 \mathrm{kcal}) / \mathrm{kg}$ body weight to $364 \mathrm{~kJ}(87 \mathrm{kcal}) /$ kg body weight (Shizgal \& Martin, 1988; Frankenfield et al. 1994; Uehara et al. 1999). These studies illustrate that assigning a set value on a per $\mathrm{kg}$ body weight basis, e.g. $84 \mathrm{~kJ}(20 \mathrm{kcal})$, may result in marked under- or overfeeding in a proportion of patients in the ITU.

\section{Measured energy expenditure}

The estimation of energy requirements is so challenging in some conditions, e.g. critical illness, obesity and liver disease, that it is recommended that expenditure be measured on an individual basis by indirect calorimetry (American Society for Parenteral and Enteral Nutrition Board of Directors, 2002). However, the equipment is not readily available in the UK, and there are a number of technical and practical considerations that need to be taken into account to ensure accurate and reliable measurements, 
recently summarised by Branson \& Johannigman (2004). Conditions should be standardised so that comparisons with future measurements under the same conditions will be meaningful. During measurements it is therefore important to prevent interaction between patient, healthcare professionals or visitors and to avoid procedures that will influence accuracy, e.g. haemo-dialysis or filtration. It is difficult to determine how long measurements should continue, although achieving a steady-state (i.e. change in $\mathrm{V}_{\mathrm{O}_{2}}$ of $<5 \%$ from 1 min to the next) improves the validity of measurements (Brandi et al. 1997; McClave et al. 2003). In metabolically-stable patients it has been shown that a steady-state period of $5 \mathrm{~min}$ (Petros \& Engelmann, 2001) or $2 \times 15 \mathrm{~min}$ is sufficient to predict $24 \mathrm{~h}$ REE (Behrendt et al. 1991). In metabolically-unstable patients, however, longer periods of from $30 \mathrm{~min}$ to $2 \mathrm{~h}$ may be required (Smyrnios et al. 1997; Branson \& Johannigman, 2004). Generally, clinically-stable patients will require shorter and less-frequent measurements than those who are more unstable, e.g. those with spiking pyrexia or haemodynamic instability and those in the immediate postoperative state (Weissman et al. 1989). While it may seem an appropriate variable, it appears that injury severity score and other measures of severity of illness are not reliable as predictors of energy requirements in patients in the ITU. Several studies have reported that REE cannot be predicted by the injury severity score or the APACHE II severity of illness score (Vermeij et al. 1989; Rodriguez et al. 1995; Boulanger et al. 1994; Brandi et al. 1999), although it was not found to be the case in other studies (Swinamer et al. 1987; Brown et al. 1993; Hwang et al. 1993).

While the majority of patients in the ITU will leave the unit within $7 \mathrm{~d}$, some patients may have a protracted stay as they suffer sequential failure of various organ systems. To date, very few studies have measured energy expenditure during prolonged ITU stays. Monk et al. (1996) have measured REE in ten critically-injured patients as soon as they were haemodynamically stable and then every $5 \mathrm{~d}$ for $21 \mathrm{~d}$. In these patients TEE was found to rise to $1.55 \times$ REE on day 10 and to remain elevated throughout the study period. The same group (Plank et al. 1998) subsequently conducted a similar study on twelve patients with severe sepsis secondary to peritonitis and have reported that TEE rises to $1.25 \times \mathrm{REE}$ and again remains elevated throughout the study period. This area is one that requires further investigation.

In the ITU setting, therefore, patients who may benefit from indirect calorimetry measurements include those who fail to respond adequately to estimated nutritional requirements and patients with multi-organ failure who require prolonged ventilatory support (Brandi et al. 1997), in addition to very-underweight or obese patients. Outside the ITU setting many patients require nutrition support over prolonged periods of several months or even years, yet there is a relative lack of studies that report MEE in such patients, partly because of the lack of affordable portable equipment that can record energy expenditure over several days or weeks. Until recently, long-term measurements could only be achieved through the use of the doubly-labelled-water technique, which is both expensive and requires considerable expertise. However, recently-launched products, such as the Sensewear ${ }^{\circledR}$ armband (BodyMedia, Pittsburgh, PA, USA), may allow researchers to answer some of these questions in the future, but currently they require more validation before their use can be recommended for routine clinical practice.

\section{Clinical implications}

While it is possible to measure energy expenditure in the clinical situation, it is important to note that MEE does not necessarily equate to energy requirements. For example, if a patient in the ITU is measured while fasting and lying still MEE may underestimate TEE, as no factors have been included for dietary-induced thermogenesis or activity. Furthermore, as described earlier, energy requirements are affected by a multitude of factors that are not included in prediction equations or taken into account during measurements of energy expenditure. Examples of these factors include the goals and likely duration of nutritional support and the specific requirements of obese patients.

In the patient in the ITU meeting energy requirements does not prevent loss of lean body mass, and exceeding requirements causes metabolic complications and may precipitate organ dysfunction leading to increased ventilator dependence and length of ITU stay (Kinney \& Elwyn, 1985; Streat et al. 1987; Frankenfield et al. 1997; Hart et al. 2002; Plank \& Hill, 2003). There is therefore a question of what are the goals of nutritional support in the ITU setting. It would seem prudent to aim to minimise losses during the acute phase of illness but then to ensure adequate repletion in the recovery (anabolic) phase. A major problem with this approach, however, is that currently there are no universally-agreed definitions of under- and overfeeding.

Energy intake $>110 \%$ estimated requirements has been used as a definition by some authors (McClave et al. 1998; Alberda et al. 2002; Kan et al. 2003); however, the requirements have been estimated differently by the different authors. For example, McClave et al. (1998) and Alberda et al. (2002) have estimated requirements by adding $10 \%$ to REE measured by metabolic cart, whereas Kan et al. (2003) have estimated the requirements by adding $20 \%$ to REE. As a result of the differences in how the energy requirements have been estimated, there are considerable differences in the reported rates of 'overfeeding'. Furthermore, in a study comparing practice in thirty-two hospitals a variation between centres was found (McClave et al. 1998) in the percentage of patients being overfed, from $32 \cdot 2$ to $92 \cdot 8$, highlighting considerable differences in practice.

In relation to underfeeding, it is important to make the distinction between hypoenergetic feeding (low energy with adequate protein) and underfeeding (low energy and protein). There is some evidence that hypoenergetic feeding may be associated with better outcomes in the ITU (Ibrahim et al. 2002; Krishnan et al. 2003), especially in patients receiving parenteral nutrition (Patino et al. 1999) and obese patients (Burge et al. 1994; Choban et al. 1997; Dickerson et al. 2002). This type of outcome may not be 
achieved, however, in patients who are not obese (Villet et al. 2005). Furthermore, underfeeding, leading to marked negative $\mathrm{N}$ balance during ITU stay, may result in poorer outcomes. In a study by Martin et al. (2004) patients in intervention hospitals (nutrition intervention conducted on evidence-based guidelines) received more energy on a daily basis than those in control hospitals $(5287 \mathrm{~kJ}$ (1265 kcal) per patient $v .4172 \mathrm{~kJ}(998 \mathrm{kcal})$ per patient) and had better outcomes (shorter hospital stay, $25 \mathrm{~d} v .35 \mathrm{~d}$, $P=0.003$; reduced hospital mortality, $27 \%$ v. $37 \%$, $P=0.058$ ), although no difference in length of ITU stay was observed. However, the amount of energy received was quite low in both control and intervention patients and the authors were unable to determine the relative value of each component of the intervention. Kan et al. (2003) have defined underfeeding as $<90 \%$ of requirements (defined as $\mathrm{MEE}+20 \%$ ) and, in fifty-four patients who were ventilated, have found no differences in outcome (length of ITU and hospital stay, length of ventilator dependence) between those who were under-, adequately- or overfed. Mean energy intakes were found to vary from $6441 \mathrm{~kJ}(1541 \mathrm{kcal}) / \mathrm{d}$ in the underfed patients to $7812 \mathrm{~kJ}$ $(1869 \mathrm{kcal}) / \mathrm{d}$ in the adequately-fed patients and $8715 \mathrm{~kJ}$ $(2085 \mathrm{kcal}) / \mathrm{d}$ in the overfed patients $(\mathrm{kJ} \quad(\mathrm{kcal}) / \mathrm{kg}$ body weight per d; 104 (24.9), $127(30 \cdot 3)$ and $174(41 \cdot 5)$ respectively). Dvir et al. (2006) have found no association between negative energy balance and length of ventilation, ITU stay, hospitalisation or mortality, although negative energy balance was shown to be correlated with ITU complications. While hypoenergetic feeding may be appropriate for critically-ill patients receiving parenteral nutrition and for critically-ill obese patients receiving enteral or parenteral nutrition, it may not be appropriate in non-obese patients. Until there are universallyagreed definitions of both under- and overfeeding, the extent to which inadequate or excess energy provision influences outcomes in patients in the ITU will remain unresolved.

The metabolic response to injury has not been specifically investigated in obese individuals, although the effects are thought to be similar to those observed in patients who are not obese. Thus, although obese patients have large fat and lean body mass stores, they are likely to develop malnutrition in response to metabolic stress, particularly if their nutritional status was poor before injury or illness. Thus, nutrition support should not be withheld. However, the determination of energy requirements is particularly problematic in obese patients (Glynn et al. 1999; Horgan \& Stubbs, 2003; Frankenfield et al. 2005). Although the best predictor of BMR is body weight, there is some evidence that REE adjusted for total body weight decreases with increasing BMI in the critically ill (Zauner et al. 2006). Amato et al. (1995) have validated the formula $88 \mathrm{~kJ}$ (21 kcal)/kg body weight in obese patients. However, when compared with other predictive formulas for patients who are ventilated (Ireton-Jones et al. 1992; HBE adjusted for average weight $\times 1 \cdot 3$ ) it was found to have a poorer predictive value (Glynn et al. 1999). Whether to use actual body weight, ideal body weight or adjusted body weight remains contentious, as there is little evidence to support any particular method (Ireton-Jones, 2005; Krenitsky,
2005). For example, the $25 \%$ adjustment (i.e. $(\mathrm{ABW}-\mathrm{IBW}) \times 0 \cdot 25+\mathrm{IBW}$, where $\mathrm{ABW}$ is actual body weight and IBW is ideal body weight) was not developed on the basis of scientific study but was initially reported in a question-and-answer format in the Renal Dietitians Newsletter, a publication of the American Dietetic Association (Karkeck, 1984; Wilkens, 1984). In the light of current evidence, hypoenergetic feeding may have some advantages in critically-ill obese patients, and clinicians should avoid overfeeding metabolically-stable obese patients. Glycaemic and metabolic control and monitoring should be particularly rigorous in obese patients.

A literature review may inform the determination of energy requirements for an individual patient if there are sufficient valid data for the relevant patient group. When reviewing the literature it is necessary to take a critical approach, to be aware of the gaps in the evidence and to understand the limitations of guidelines. For many patient groups, however, there is a general lack of studies from which to make any useful recommendations. Despite the high prevalence of cerebro-vascular accident, a literature review reveals only four studies in which energy expenditure has been measured post-cerebro-vascular accident, two in ischaemic strokes (Weekes \& Elia, 1992; Finestone et al. 2003) and the other two in haemorrhagic strokes (Piek et al. 1989; Touho et al. 1990). Another area requiring more research is the effect of abnormal losses, e.g. malabsorption disorders, wounds and fistula outputs, on energy requirements. For example, in patients with high-output fistulas the energy losses can amount to $15 \%$ of their average daily energy expenditure (Reid et al. 1999), while in another study that measured energy expenditure in patients with inflammatory bowel disease (some with fistulas) no account was taken of the effect of such losses (Barot et al. 1982). Other conditions that merit more research are chronic inflammatory states, such as those that exist in patients with chronic obstructive pulmonary disease or cardiac cachexia, and the effects of different treatment modalities on the energy requirements of patients with different cancers.

The present review has shown that despite the number of studies investigating the energy requirements of different patient groups, there are still areas that require more research. In particular, the following questions need to be addressed:

if a patient is fed to energy requirements (determined by any method) will he or she have a better outcome than if he or she is not;

how do different levels of feeding (e.g. <BMR, BMR or BMR $\times$ stress factor, $84-105 \mathrm{~kJ}(20-25 \mathrm{kcal}) / \mathrm{kg}$ body weight) affect outcomes (e.g. mortality (in ITU or in hospital), period (d) on a ventilator, length of stay (d) in ITU, mobility and rehabilitation post ITU, length of hospital stay);

does feeding have to be tailored to an individual's estimated requirements or would a limited number of 'standard' regimens be sufficient, e.g. 4180, 6270 or $8360 \mathrm{~kJ}(1000,1500$ or $2000 \mathrm{kcal}) / \mathrm{d}$;

do prescriptions for energy need to be altered to reflect MEE on a day-to-day basis? Will this approach result in 
a better outcome when compared with a stable energy prescription over the same period;

what clinical variables should be used to assign specific stress factors and which should be used to monitor change? How often should variables be monitored; what are the energy requirements of patients receiving long-term nutritional support at home or in the community.

It is likely that recommendations for determining energy requirements will be different for obese and undernourished individuals and for patients at risk of re-feeding, when compared with well-nourished individuals. Similarly, different metabolic states (whether or not patients are hospitalised) are also likely to have a profound effect on requirements.

In clinical practice, therefore, it is important to recognise that estimated energy requirements are only a starting point, and that all clinicians should regularly review their patients to ensure they are meeting their nutritional goals and to evaluate the effectiveness of nutritional support. Energy requirements may change as a result of changes in a patient's clinical condition, nutritional status and prognosis, and to date there appear to be few studies that measure the changes in energy expenditure that occur as a patient's condition changes. Furthermore, the likely duration of nutrition support needs to be considered. In the short term, a period of slight over- or underfeeding may not be problematic in metabolically-stable individuals, although it is unlikely to be the case in the critically ill. Many patients receive long-term feeding at home or in other community settings, and even in the metabolicallystable individual prolonged over- or underfeeding is likely to have adverse clinical effects, especially in the absence of adequate monitoring and follow-up.

\section{Acknowledgements}

The author would like to thank Dr Clare Soulsby for her helpful discussions in the preparation of this manuscript.

\section{References}

Alberda C, Snowden L, McCargar L \& Gramlich L (2002) Energy requirements in critically ill patients: how close are our estimates? Nutrition in Clinical Practice 17, 38-42.

Amato P, Keating KP, Quercia RA \& Karbonic J (1995) Formulaic methods of estimating caloric requirements in mechanical ventilated obese patients: a reappraisal. Nutrition in Clinical Practice 10, 229-230.

American Society for Parenteral and Enteral Nutrition Board of Directors (2002) Guidelines for the use of parenteral and enteral nutrition in adult and pediatric patients. Journal of Parenteral and Enteral Nutrition 26, Suppl., 1SA-138SA.

Barak N, Wall-Alonso E \& Sitrin MD (2002) Evaluation of stress factors and body weight adjustments currently used to estimate energy expenditure in hospitalized patients. Journal of Parenteral and Enteral Nutrition 26, 231-238.

Barot LR, Rombeau JL, Feurer ID \& Mullen JL (1982) Caloric requirements in patients with inflammatory bowel disease. Annals of Surgery 195, 214-218.
Behrendt W, Surmann M, Raumanns J \& Giani G (1991) How reliable are short-term measurements of oxygen uptake in polytraumatized and long-term ventilated patients? Infusionstherapie 18, 20-24.

Benedict FG (1928) Basal metabolism data on normal men and women (series II) with some considerations on the use of prediction standards. American Journal of Physiology 85, 607620.

Boulanger BR, Nayman R, McLean RF, Phillips E \& Rizoli SB (1994) What are the clinical determinants of early energy expenditure in critically injured adults? Journal of Trauma 37, 969-974.

Brandi LS, Bertolini R \& Calafa M (1997) Indirect calorimetry in critically ill patients: clinical applications and practical advice. Nutrition 13, 349-358.

Brandi LS, Bertolini R, Santini L \& Cavani S (1999) Effects of ventilator resetting on indirect calorimetry measurement in the critically ill surgical patient. Critical Care Medicine 27, 531539.

Branson RD \& Johannigman JA (2004) The measurement of energy expenditure. Nutrition in Clinical Practice 19, 622-636.

Brown PE, McClave SA, Hoy NW, Short AF, Sexton LK \& Meyer KL (1993) The Acute Physiology and Chronic Health Evaluation II classification system is not a valid marker for physiologic stress in the critically ill patient. Critical Care Medicine 21, 363-367.

Bruder N, Raynal M, Pellissier D, Courtinat C \& Francois G (1998) Influence of body temperature, with or without sedation, on energy expenditure in severe head-injured patients. Critical Care Medicine 26, 568-572.

Burge JC, Goon A, Choban PS \& Flancbaum L (1994) Efficacy of hypocaloric total parenteral nutrition in hospitalized obese patients: a prospective, double-blind randomized trial. Journal of Parenteral and Enteral Nutrition 18, 203-207.

Carlsson M, Nordenstrom J \& Hedenstierna G (1984) Clinical implications of continuous measurement of energy expenditure in mechanically ventilated patients. Clinical Nutrition 3, 103110.

Casati A, Colombo S, Leggieri C, Muttini S, Capocasa T \& Gallioli G (1996) Measured versus calculated energy expenditure in pressure support ventilated ICU patients. Minerva Anesthiosiology 62, 165-170.

Cheng $\mathrm{CH}$, Chen $\mathrm{CH}$, Wong Y, Lee BJ, Kan MN \& Huang YC (2002) Measured versus estimated energy expenditure in mechanically ventilated critically ill patients. Clinical Nutrition 21, 165-172.

Choban PS, Burge JC, Scales D \& Flancbaum L (1997) Hypoenergetic nutrition support in hospitalized obese patients: a simplified method for clinical application. American Journal of Clinical Nutrition 66, 546-550.

Cortes V \& Nelson LD (1989) Errors in estimating energy expenditure in critically ill surgical patients. Archives of Surgery 124, 287-290.

Daly JM, Heymsfield SB, Head CA, Harvey LP, Nixon DW, Katzeff H \& Grossman GD (1985) Human energy requirements: over estimation by widely used prediction equation. American Journal of Clinical Nutrition 42, 1170-1174.

Department of Health (1991) Dietary Reference Values for Food Energy and Nutrients for the United Kingdom. Report on Health and Social Subjects no. 41. London: H. M. Stationery Office.

Dickerson RN, Boschert KJ, Kudsk KA \& Brown RO (2002) Hypocaloric enteral tube feeding in critically ill obese patients. Nutrition 18, 241-246.

Dvir D, Cohen J \& Singer P (2006) Computerized energy balance and complications in critically ill patients: an observational study. Clinical Nutrition 25, 37-44. 
Elia M (1990) Artificial nutritional support. Medicine International 82, 3392-3396.

Elia M (1995) Changing concepts of nutrient requirements in disease: implications for artificial nutritional support. Lancet 345, 1279-1284

Elia M (2003) The MUST Report. Nutritional Screening of Adults: A Multidisciplinary Responsibility. Redditch. Worcs.: Malnutrition Advisory Group of BAPEN.

Elia M \& Jebb SA (1992) Changing concepts of energy requirements of critically ill patients. Current Medical Literature in Clinical Nutrition 1, 35.

Elwyn DH, Kinney JM \& Askanazi J (1981) Energy expenditure in surgical patients. Surgical Clinics of North America 61, $545-555$.

Faisy C, Guerot E, Diehl J-L, Labrousse J \& Fagon J-Y (2003) Assessment of resting energy expenditure in mechanically ventilated patients. American Journal of Clinical Nutrition 78, 241-249.

Food and Agriculture Organization/World Health Organization/ United Nations University (1985) Energy and Protein Requirements. Report of a Joint FAO/WHO/UNU Expert Consultation. WHO Technical Report Series no. 724. Geneva: WHO.

Finestone HM, Greene-Finestone LS, Foley NC \& Woodbury MG (2003) Measuring longitudinally the metabolic demands of stroke patients: resting energy expenditure is not elevated. Stroke 34, 502-507.

Flancbaum L, Choban PS, Sambucco S, Verducci J \& Burge JC (1999) Comparison of indirect calorimetry, the Fick method, and prediction equations in estimating the energy requirements of critically ill patients. American Journal of Clinical Nutrition 69, 461-466.

Franch-Arcas G, Plank LD, Monk DN, Gupta R, Maher K, Gillanders L \& Hill GL (1994) A new method for the estimation of the components of energy expenditure in patients with major trauma. Endocrinology and Metabolism 30, E1002E1009.

Frankenfield DC, Omert LA, Wiles CE 3rd, Bagley SM, Goodarzi S \& Siegel JH (1994) Correlation between measured energy expenditure and clinically obtained variables in trauma and sepsis patients. Journal of Parenteral and Enteral Nutrition 18, 398-403.

Frankenfield DC, Smith JS \& Cooney RN (1997) Accelerated nitrogen loss after traumatic injury is not attenuated by achievement of energy balance. Journal of Parenteral and Enteral Nutrition 21, 324-329.

Frankenfield DC, Roth-Yousy L \& Compher C (2005) Comparison of predictive equations for resting metabolic rate in healthy nonobese and obese adults: a systematic review. Journal of the American Dietetic Association 105, 775-789.

Glynn CC, Greene GW, Winkler MF \& Albina JE (1999) Predictive versus measured energy expenditure using limits-ofagreement analysis in hospitalized, obese patients. Journal of Parenteral and Enteral Nutrition 23, 147-154.

Green CJ, Campbell IT, McClelland P, Hutton JL, Ahmed MM \& Helliwell TR (1995) Energy and nitrogen balance and changes in mid upper arm circumference with multiple organ failure. Nutrition 11, 739-746.

Greenblatt SH, Long CL, Blakemore WS, Dennis RS, Rayort M \& Geiger JW (1989) Catabolic effect of dexamethasone in patients with major head injuries. Journal of Parenteral and Enteral Nutrition 13, 372-376.

Hanhela R, Mustonen A, Korhonen I \& Salomaki T (1999) The effects of two rewarming strategies on heat balance and metabolism after coronary bypass surgery with moderate hypothermia. Acta Anaesthesiologica Scandinavica 43, 979988.
Harris JA \& Benedict FG (1919) A Biometric Study of Basal Metabolism in Man. Washington, DC: Carnegie Institute.

Hart DW, Wolf SE, Herndon DN, Chinkes DL, Lal SO, Obeng MK, Beauford RB \& Mlcak RP (2002) Energy expenditure and caloric balance after burn: increased feeding leads to fat rather than lean mass accretion. Annals of Surgery 235, 152 161.

Henry CJK (2005) Basal metabolic rate studies in humans: measurement and development of new equations. Public Health Nutrition 8, 1133-1152.

Horgan GW \& Stubbs J (2003) Predicting basal metabolic rate in the obese is difficult. European Journal of Clinical Nutrition 57, 335-340.

Hunter DC, Jaksic T, Lewis D, Benotti PN, Blackburn GL \& Bistrian BR (1988) Resting energy expenditure in the critically ill: estimations versus measurement. British Journal of Surgery 75, 875-878.

Hwang TL, Huang SL \& Chen MF (1993) The use of indirect calorimetry in critically ill patients - the relationship of measured energy expenditure to Injury Severity Score. Septic Severity Score, and APACHE II Score. Journal of Trauma 34, 247-251.

Ibrahim EH, Mehringer L, Prentice D, Sherman G, Schaiff R, Fraser V \& Kollef MH (2002) Early versus late enteral feeding of mechanically ventilated patients: results of a clinical trial. Journal of Parenteral and Enteral Nutrition 26, 174-181.

Ireton-Jones CS (2005) Adjusted body weight. Con: Why adjust body weight in energy-expenditure calculations? Nutrition in Clinical Practice 20, 474-479.

Ireton-Jones CS, Turner WW, Liepa GU \& Baxter CR (1992) Equations for the estimation of energy expenditure in patients with burns with special reference to ventilatory status. Journal of Burn Care and Rehabilitation 13, 330-333.

Johnson RK, Hildreth HG, Contompasis SH \& Goran MI (1997) Total energy expenditure in adults with cerebral palsy as assessed by doubly labeled water. Journal of the American Dietetic Association 97, 966-970.

Kan MN, Chang HH, Sheu WF, Cheng CH, Lee BJ \& Huang YC (2003) Estimation of energy requirements for mechanically ventilated, critically ill patients using nutritional status. Critical Care 7, R108-R115.

Karkeck J (1984) Adjusted body weight for obesity. American Dietetic Association Renal Practice Group Newsletter 3, 6.

Kinney JM \& Elwyn DH (1985) Protein metabolism in the traumatized patient. Acta Chirurgica Scandinavica 522, Suppl., $45-56$.

Krenitsky J (2005) Adjusted body weight. Pro: Evidence to support the use of adjusted body weight in calculating calorie requirements. Nutrition in Clinical Practice 20, 468-473.

Kreymann KG, Berger MM, Deutz NEP, Hiesmayr M, Jolliet P, Kazandjiev G, Nitenberg G, van den Berghe G \& Wernerman G (2006) ESPEN Guidelines on enteral nutrition: intensive care. Clinical Nutrition 25, 210-223.

Krishnan JA, Parce PB, Martinez A, Diette GB \& Brower RG (2003) Caloric intake in medical ICU patients: consistency of care with guidelines and relationship to clinical outcomes. Chest 124, 297-305.

Liggett SB \& Renfro AD (1990) Energy expenditures of mechanically ventilated nonsurgical patients. Chest 98, 524526.

Lobo DN, Macafee DAL \& Allison SP (2006) How perioperative fluid balance influences postoperative outcomes. Best Practice and Research Clinical Anaesthesiology 20, 439-455.

Long CL, Schaffel N, Geiger JW, Schiller WR \& Blakemore WS (1979) Metabolic response to injury and illness: estimation of energy and protein needs from indirect calorimetry and 
nitrogen balance. Journal of Parenteral and Enteral Nutrition 3, 452-456.

McClave SA, Lowen CC, Kleber MJ, Nicholson JF, Jimmerson SC, McConnell JW \& Jung LJ (1998) Are patients fed appropriately according to their caloric requirements? Journal of Parenteral and Enteral Nutrition 22, 375-381.

McClave SA, Spain DA, Skolnick JL, Lowen CC, Kieber MJ, Wickerham PS, Vogt JR \& Looney SW (2003) Achievement of steady state optimizes results when performing indirect calorimetry. Journal of Parenteral and Enteral Nutrition 27, 16-20.

McCrory MA, Kim HR, Wright NC, Lovelady CA, Aitkens S \& Kilmer DD (1998) Energy expenditure, physical activity, and body composition of ambulatory adults with hereditary neuromuscular disease. American Journal of Clinical Nutrition 67, $1162-1169$.

Madden A \& Wicks C (1994) A Practical Guide to Nutrition in Liver Disease. Birmingham: Liver Interest Group of the British Dietetic Association.

Martin MM, Doig GS, Heyland DK, Morrison T \& Sibbald WJ (2004) Multicentre, cluster-randomized clinical trial of algorithms for critical-care enteral and parenteral therapy (ACCEPT), Canadian Medical Association Journal 170, 197204.

Mifflin MD, St Joer ST, Hill LA, Scott BJ, Daugherty SA \& Koh YO (1990) A new predictive equation for resting energy expenditure in healthy individuals. American Journal of Clinical Nutrition 51, 241-247.

Miller MD, Daniels LA, Bannerman E \& Crotty M (2005) Resting energy expenditure measured longitudinally following hip fracture compared to predictive equations: is an injury adjustment required? British Journal of Nutrition 94, 976-982.

Monk DN, Plank LD, Franch-Arcas G, Finn PJ, Streat SJ \& Hill GL (1996) Sequential changes in the metabolic response in critically injured patients during the first 25 days after blunt trauma. Annals of Surgery 223, 395-405.

National Institute for Health and Clinical Excellence (2006) Nutrition Support for Adults: Oral Nutrition Support, Enteral Tube Feeding and Parenteral Nutrition. London: NICE.

Patino JF, de Pimiento SE, Vergara A, Savino P, Rodriguez M \& Escallon J (1999) Hypocaloric support in the critically ill. World Journal of Surgery 23, 553-559.

Petros S \& Engelmann L (2001) Validity of an abbreviated indirect calorimetry protocol for measurement of resting energy expenditure in mechanically ventilated and spontaneously breathing critically ill patients. Intensive Care Medicine 27, 1164-1168.

Piek J, Zanke T, Sprick C \& Bock WJ (1989) Resting energy expenditure in patients with isolated head injuries and spontaneous intracranial haemorrhages. Clinical Nutrition 8, 347351.

Plank LD, Connolly AB \& Hill GL (1998) Sequential changes in the metabolic response in severely septic patients during the first 23 days after the onset of peritonitis. Annals of Surgery 228, 146-158.

Plank LD \& Hill GL (2003) Energy balance in critical illness. Proceedings of the Nutrition Society 62, 545-552.

Reeves MM \& Capra S (2003) Predicting energy requirements in the clinical setting: are current methods evidence based? Nutrition Reviews 61, 143-151.

Reid C \& Campbell I (2001) High energy deficits in MODS patients are associated with prolonged length of stay (LOS) but not mortality. Clinical Nutrition 20, Suppl., A133.

Reid CL, Shipley K, Jennings G, Elia M \& Campbell IT (1999) Energy and nitrogen content of abnormal losses from intensive care patients. Clinical Nutrition 18, Suppl. A87.

Roberts RJ (1995) Can self-reported data accurately describe the prevalence of overweight? Public Health 95, 275-284.
Rodriguez DJ, Sandoval W \& Clevenger FW (1995) Is measured energy expenditure correlated to Injury Severity Score in major trauma patients? Journal of Surgical Research 59, 455459.

Rowland ML (1990) Self-reported weight and height. American Journal of Clinical Nutrition 52, 1125-1133.

Ruivo A, Marques-Vidal P \& Camilo ME (2004) Can we believe in reported height and weight? Clinical Nutrition 23, 769.

Shizgal HM \& Martin MF (1988) Caloric requirement of the critically ill septic patient. Critical Care Medicine 16, 312317.

Smyrnios NA, Curley FJ \& Shaker KG (1997) Accuracy of 30minute indirect calorimetry studies in predicting 24-hour energy expenditure in mechanically ventilated, critically ill patients. Journal of Parenteral and Enteral Nutrition 21, 168174.

Streat SJ, Beddoe AH \& Hill GL (1987) Aggressive nutritional support does not prevent protein loss despite fat gain in septic intensive care patients. Journal of Trauma 27, 262-266.

Swinamer DL, Phang PT, Jones RL, Grace M \& King EG (1987) Twenty-four hour energy expenditure in critically ill patients. Critical Care Medicine 15, 637-643.

Terao Y, Miura K, Saito M, Sekino M, Fukusaki M \& Sumikawa K (2003) Quantitative analysis of the relationship between sedation and resting energy expenditure in postoperative patients. Critical Care Medicine 31, 830-833.

Todorovic VE \& Micklewright A (editors) (1997) Adult requirements. In A Pocket Guide to Clinical Nutrition, pp. 3.1-3.3. Birmingham: BDA.

Todorovic VE \& Micklewright A (editors) (2004) Adult requirements. In A Pocket Guide to Clinical Nutrition, 3rd ed., pp. 3.1-3.8. Birmingham: BDA.

Toth MJ, Fishman PS \& Poehlman ET (1997) Free-living daily energy expenditure in patients with Parkinson's disease. Neurology 48, 88-91.

Touho H, Karasawa J, Shishido H, Morisako T, Numazawa S, Yamada K, Nagai S \& Shibamoto K (1990) Measurement of energy expenditure in acute stage of cerebrovascular diseases. Neurologia Medico-Chirurgica 30, 541-545.

Uehara M, Plank LD \& Hill GL (1999) Components of energy expenditure in patients with severe sepsis and major trauma: a basis for clinical care. Critical Care Medicine 27, 1295-1302.

van Lanschot JJB, Feenstra BWA, Vermeij CG \& Bruining HA (1986) Calculation versus measurement of total energy expenditure. Critical Care Medicine 14, 981-985.

Vermeij CG, Feenstra BWA, van Lanschot JJB \& Bruining HA (1989) Day-to-day variability of energy expenditure in critically ill surgical patients. Critical Care Medicine 17, 623-626.

Villet S, Chiolero RL, Bollmann MD, Revelly JP, Cayeux RN, Delarue J \& Berger MM (2005) Negative impact of hypocaloric feeding and energy balance on clinical outcome in ICU patients. Clinical Nutrition 24, 502-509.

Wallace BH, Caldwell FT \& Cone FB (1992) Ibuprofen lowers body temperature and metabolic rate of humans with burn injury. Journal of Trauma 32, 154-157.

Weekes CE \& Elia M (1992) Resting energy expenditure and body composition following cerebro-vascular accident. Clinical Nutrition 11, 18-22.

Weijs PJM \& Kruizenga HM (2006) Evidence for stress and activity factors for calculating energy expenditure of intensive care and other patients. Clinical Nutrition 25, 137.

Weissman C \& Kemper M (1992) Assessing hypermetabolism and hypometabolism in the postoperative critically ill patient. Chest 102, 1566-1571.

Weissman C, Kemper M, Elwyn DH, Askanazi J, Hyman AI \& Kinney JM (1986) The energy expenditure of the mechanically ventilated critically ill patient: an analysis. Chest 89, 254-259. 
Weissman C, Kemper M \& Hyman AI (1989) Variation in the resting metabolic rate of mechanically ventilated critically ill patients. Anesthesiological Analgesia 68, 457461.

Wilkens K (1984) Adjustment for obesity. American Dietetic Association Renal Practice Group Newsletter 3, 6.
Wilmore DW (1977) The Metabolic Management of the Critically Ill. New York: Plenum Publishing Corporation.

Zauner A, Schneeweiss B, Kneidinger N, Lindner G \& Zauner C (2006) Weight-adjusted resting energy expenditure is not constant in critically ill patients. Intensive Care Medicine 32, 428434. 